\title{
Structural Stress-Fatigue Life Curve Improvement of Spot Welding Based on Quasi-Newton Method
}

\author{
Yahang Qin, Shoune Xiao, Liantao Lu, Bing Yang, Xiangjie Li and Guangwu Yang*
}

\begin{abstract}
$\Delta \mathrm{F}-\mathrm{N}$ curves are usually used to predict the fatigue life of spot welding in engineering, but they are time-consuming and laborious and not universal. For the purpose of predicting the fatigue life of spot welding accurately and efficiently, tensile-shear fatigue tests were conducted to obtain the fatigue life of spot-welded specimens with different sheet thicknesses combinations. These specimens were simulated by using the finite element method, and the structural stress was theoretically calculated. In the double logarithmic coordinate system, the structural stress-fatigue life $(\mathrm{S}-\mathrm{N})$ curve of spot welding was fitted by the least-squares method, based on the quasi-Newton method. The square of the correlation coefficient of the S-N curve was taken as the optimization objective, with the correction coefficients of force, bending moment, spot welding diameter, and sheet thickness as the variables. During the optimization process, three different ways were utilized to get three optimized spot welding S-N curves, which are suitable for different situations. The results show that the fitting effect of the $\mathrm{S}-\mathrm{N}$ curve is improved, the data points are more compact, and the optimization effect is significant. These $\mathrm{S}-\mathrm{N}$ curves can be used to predict the fatigue life, which provide the basis for practical engineering application.
\end{abstract}

Keywords: Spot welding, Structural stress, S-N curve, Quasi-Newton method, Correction coefficient

\section{Introduction}

Fatigue and fracture are the main causes of failure of engineering structures and specimens. Fatigue fracture failure involves many aspects, such as cyclic loads or disturbed loads, the formation and expansion of material defects, and the influence of the service environment, etc. Spot welding is commonly used in stainless-steel car bodies and has been widely applied in to automotive, aerospace, and railway vehicles, making it necessary to study the anti-fatigue performance of spot-welded structures. Because there are various forms of welding, it is not easy to determine the load parameters under different loading conditions, and research methods for welding fatigue strength are also different.

\footnotetext{
*Correspondence: 191797203@qq.com; gwyang@home.swjtu.edu.cn State Key Laboratory of Traction Power, Southwest Jiaotong University, Chengdu 610031, China
}

Using equivalent structural stresses at the spot-welded edges, Kang et al. [1,2] proposed a fatigue prediction method for spot-welded joints in automotive body structures by substituting the stress components in the von Mises formula for the local structural stresses near the spot welding. Radaj [3] indicated that the fatigue durability of welded joints with different structures and different load forms could be evaluated by numerical calculation and analysis of local stresses on the plate around the welded joint. After that, Rupp [4] reported how to calculate these structural stresses and perform fatigue life calculations on welded joints based on maximum and minimum stresses and the load spectrum. Kang et al. $[5,6]$ proposed a data processing procedure to optimize the empirical factors in Rupp's structural stress calculation, the optimized results demonstrated that the degree of scatter is less than that of previous calculations with initial empirical factors, and the fatigue life prediction using this procedure is well correlated with test results. 
The performance of spot welding has been analyzed by means of simulation, and the model was modified by combining it with the results of modal and component tests [7-13]. By changing the spot-welding parameters through numerous component tests, the influence of different welding parameters on the fatigue performance of the solder joint was investigated [14-18].

Adib [19] studied the mechanical behavior of spot welding under the tensile-shear load for one, three, and five spot welds in detail, and the volumetric approach was applied to find fatigue life duration of welded spots. Through experimental examination, Choi et al. [20] studied the fatigue behavior of spot-welded triple plates and proposed a fatigue life prediction by using the crack opening angle (COA) around the spot welding. Referring to the studies of Kan [21] and Oh [22], Pan and Sheppard [23] discussed the nature of the stresses and strains around the welded joint and studied the relationship between strain and fatigue life. Finally, they developed a fatigue life prediction method based on strain. Dong et al. [24-26] presented a structural stress definition that is insensitive to mesh size. The definition is consistent with elementary structural mechanics theory and provides an effective measure of the stress state associated with the fatigue behavior of welded joints in the form of both membrane and bending components. Wang et al. [27] developed an empirical three-stage initiation-propagation (TSIP) model that can predict the anti-fatigue performance of spot welding under a constant amplitude tensile-shear load. They discussed the improvements of the anti-fatigue performance caused by changes in the welding geometry, residual stress, and material property with the aid of the model. Lee et al. [28] expressed the ultimate loads in terms of the base metal yield strength and specimen geometries and then presented a master overload failure curve for a single spot-welded specimen in a mixed-mode load domain. Recasting the load vs. fatigue life relations experimentally obtained, they finally succeeded in predicting the fatigue life of various spotwelded specimens with a single parameter.

Research on the fatigue characteristics of spot welding is mainly based on modal analysis, fracture mechanics, or the structural stress method. Fatigue analysis using modal analysis requires numerous experiments, entailing high costs, and the modal frequency of the structure is not easy to obtain $[29,30]$. Fatigue analysis based on fracture mechanics requires establishing a detailed finite element model to analyze crack growth and deduce the stress intensity factor [31-33]. The above process is complicated and not suitable for the simple life prediction in engineering practice. By contrast, the structural stress method is relatively simple and effective, greatly reducing the workload in engineering application.
In this paper, a finite element model of spot welding based on the structural stress method is established. The relation between the structural stress and the fatigue life of spot-welded specimens is described. For the fitted fatigue performance curve, the influence of each parameter on the fitting effect of the curve is analyzed, thereby obtaining a curve with guiding significance to engineering practice.

\section{Fatigue Analysis Theory}

Figure 1 shows a typical spot-welded structure, with the shaded portion being the weld nugget. In the finite element analysis, two sheets are simulated by the shell elements and the weld nugget is simulated by the CBAR beam element, which is perpendicular to the neutral layer and connects point 1 to point 2 . To obtain more accurate force values and moment values for the beam element nodes, a spot-welding model should be established in the calculation. As shown in Figure 1, the axial direction of the beam element is taken as the $Z$ direction in the FE (finite element) fatigue, but it is worth noting that, in MSC NASTRAN, the axial direction of the beam element is the $X$ direction. Therefore, before performing the fatigue analysis, it is necessary to transform the results of the beam element's forces and moments between the coordinate systems. The specific conversion process is given in Table 1.

The structural stresses on the inner surfaces of the two sheets are calculated by using the transformed beam element nodal forces and moments (except $M_{Z}$ ). When considering the fatigue strength of the base metal around the weld nugget, the radial stress on the contact surface of the two sheets around the weld nugget is taken as the structural stress. However, when considering the fatigue

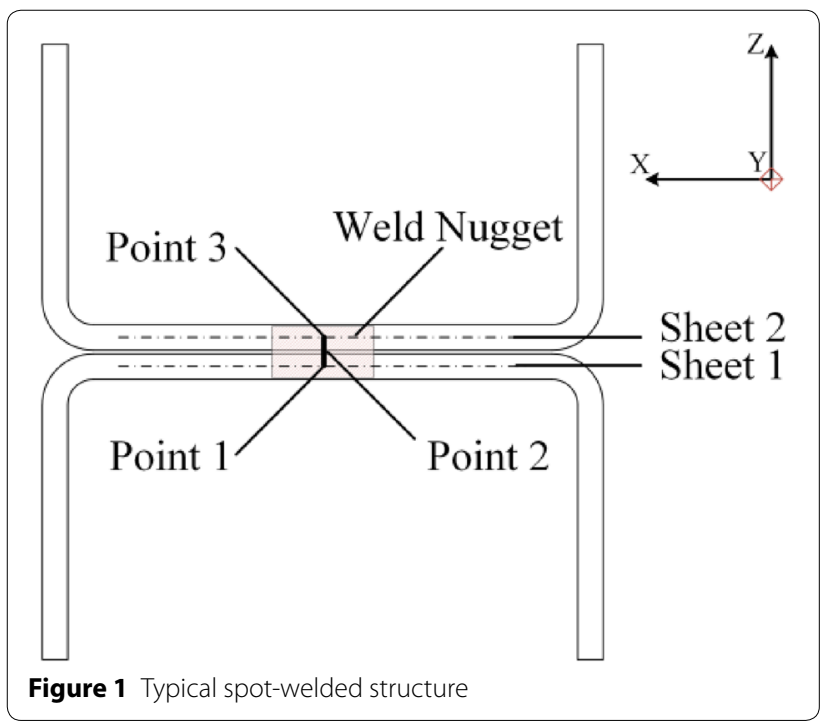


Table 1 Transformation of nodal forces in FE fatigue

\begin{tabular}{|c|c|c|c|c|}
\hline \multicolumn{2}{|l|}{ Point 1} & \multicolumn{2}{|l|}{ Point 2} & \multirow{2}{*}{$\begin{array}{l}\text { Point } 3 \\
\text { FE-fatigue }\end{array}$} \\
\hline FE fatigue & NASTRAN CBAR & FE fatigue & NASTRAN CBAR & \\
\hline FX1 & $-Z$ force & $\mathrm{FX} 2$ & $Z$ force & FX1 \\
\hline FY1 & $Y$ force & $\mathrm{FY} 2$ & $-Y$ force & FY1 \\
\hline FZ1 & $X$ force & $F Z 2$ & $-X$ force & $F Z 1$ \\
\hline$M \times 1$ & $-Z$ moment1 & $M \times 2$ & $Z$ moment2 & $\left(M X 1^{*} t 2+M X 2^{*} t 1\right) /(t+t 2)$ \\
\hline MY1 & $-Y$ moment1 & MY2 & $Y$ moment2 & $\left(M Y 1 * t 2+M Y 2^{*} t 1\right) /(t 1+t 2)$ \\
\hline MZ1 & $X$ moment & MZ2 & $-X$ moment & $\left(M Z 1{ }^{*} t 2+M Z 2^{*} t 1\right) /(t 1+t 2)$ \\
\hline
\end{tabular}

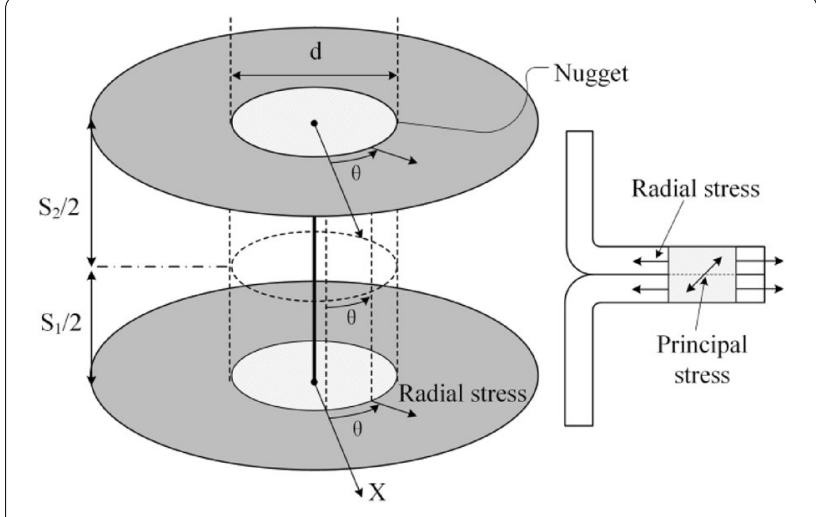

Figure 2 Structural stress calculation model

$$
\begin{aligned}
& \sigma_{\max }\left(M_{x 1}\right)=K_{1}\left(\frac{1.872 M_{x 1}}{d s_{1}^{2}}\right), \\
& \sigma_{\max }\left(M_{y 1}\right)=K_{1}\left(\frac{1.872 M_{y 1}}{d s_{1}^{2}}\right),
\end{aligned}
$$

where $d$ is the diameter of the weld nugget, $s_{1}$ is the thickness of sheet $1, K_{1}=0.6 \sqrt{s_{1}}$ is the empirical correction coefficient, and $\theta$ is the angle of the calculated stress.

When $F_{z 1}>0$, the axial force of the weld nugget is a tensile force, which will cause fatigue damage. Consequently, the influence of the axial force should be considered:

$$
\sigma\left(F_{z 1}\right)=K_{1}\left(\frac{1.744 F_{z 1}}{s_{1}^{2}}\right) .
$$

strength of the weld nugget, the principal stress of the weld nugget at the joint cross section is taken as the structural stress, and the principal stress is determined by the shear stress and normal stress at the weld nugget. Figure 2 shows the calculation model of the equivalent structural stress of the base metal and the weld nuggets. The equations for calculating the specific equivalent structure of the base metal are as follows.

Taking sheet 1 as an example, the structural stress of the base material can be expressed by

$$
\begin{aligned}
\sigma_{v 1} v= & -\sigma_{\max }\left(F_{x 1}\right) \cos \theta-\sigma_{\max }\left(F_{y 1}\right) \sin \theta+\sigma_{\max }\left(F_{z 1}\right) \\
& +\sigma_{\max }\left(M_{x 1}\right) \sin \theta-\sigma_{\max }\left(M_{y 1}\right) \cos \theta,
\end{aligned}
$$

where

$$
\begin{gathered}
\sigma_{\max }\left(F_{x 1}\right)=\frac{F_{x 1}}{\pi d s_{1}}, \\
\sigma_{\max }\left(F_{y 1}\right)=\frac{F_{y 1}}{\pi d s_{1}},
\end{gathered}
$$

When $F_{z 1} \leq 0$, the axial force of the weld nugget is a compressive force, hence no fatigue will occur. Therefore, the influence of the axial force can be ignored:

$$
\sigma\left(F_{z 1}\right)=0 .
$$

For the fatigue strength of the base metal, the equations for calculating the structural stress are given above. By solving for the structural stress and using probability and statistics methods, the stress-life distribution can be obtained. These data can be fitted to establish the structural stress-fatigue life $(\mathrm{S}-\mathrm{N})$ curves of the base metal, which are suitable for the fatigue design and life prediction of the spot-welded structures.

\section{Experimental Procedures and Finite Element Simulation}

\subsection{Fatigue Tests}

Austenitic stainless steel was used in this study because of its good weldability and corrosion resistance. The base metals (BMs) used for comparison were stainless steels of spot-welded bodies in railway vehicles. They were 1.4318 and $1.4318+$ C850 austenitic stainless steels in 
Table 2 Chemical compositions of 1.4318 austenitic stainless steel

\begin{tabular}{|c|c|c|c|c|c|c|c|c|}
\hline \multirow{2}{*}{$\frac{\text { Base metal }}{\mathrm{X} 2 \mathrm{CrNiN} 18-7}$} & \multicolumn{8}{|c|}{ Chemical composition (wt\%) } \\
\hline & C & $\mathrm{Si}$ & $\mathrm{Mn}$ & $P_{\max }$ & S & $\mathrm{Ni}$ & $\mathrm{Cr}$ & N \\
\hline & $<0.03$ & $\leq 1$ & $\leq 2$ & $\leq 0.045$ & $\leq 0.015$ & $6-8$ & $16.5-18.5$ & $0.1-0.2$ \\
\hline
\end{tabular}

Table 3 Physical mechanical properties of 1.4318 and $1.4318+\mathrm{C} 850$ austenitic stainless steels

\begin{tabular}{lllllc}
\hline Base metal & Number & $\begin{array}{l}\text { Density } \\
\left(\mathbf{k g} / \mathbf{m}^{\mathbf{3}}\right)\end{array}$ & $\begin{array}{l}\text { Poisson's } \\
\text { ratio }\end{array}$ & $\begin{array}{l}\text { Yield } \\
\text { strength } \\
(\mathbf{M P a})\end{array}$ & $\begin{array}{l}\text { Tensile } \\
\text { strength } \\
(\mathbf{M P a})\end{array}$ \\
\hline X2CrNiN18-7 & 1.4318 & 7850 & 0.3 & 330 & 630 \\
& $1.4318+\mathrm{C} 850$ & 7850 & 0.3 & 500 & 1010 \\
\hline
\end{tabular}
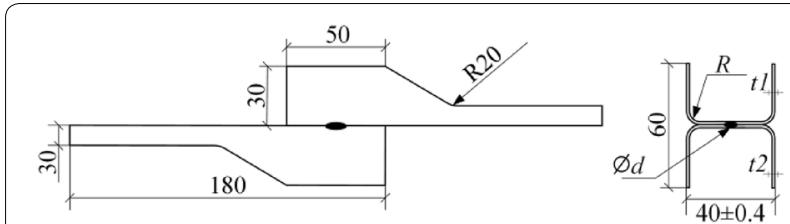

Figure 3 Dimensions for spot-welded specimen

EN10088-2 [34], the chemical compositions and physical mechanical properties of which are listed in Tables 2 and 3.

Tensile-shear fatigue tests of spot-welded specimens with different sheet thicknesses were conducted under two load ratios $(r=0.1$ and 0.5$)$. The commonly used sheet thickness combinations were $0.8+1.2,0.8+2.5$, $1.5+1.5,1.5+2.0$, and $2.0+2.0$. Except for the sheet thickness and welding nugget diameter, other main parameters such as shape and length remained constant. The shape and dimensions of spot-welded specimens are shown in Figure 3. The welding nugget diameters and chamfer circle radii of different sheet thicknesses are given in Table 4. As shown in Figure 4, the tensile-shear tests were performed using a RUMUL TESTRONIC high-frequency testing machine (Switzerland).

Five kinds of spot-welded specimens were tested on a high-frequency fatigue testing machine. The fatigue data of the specimens with $1.5+1.5 \mathrm{~mm}$ thickness combination under two load ratios $(r=0.1$ and 0.5$)$ were obtained from the tensile-shear fatigue testing, and the other specimens were only loaded under one load ratio $(r=0.5)$. All fatigue test results are distinguished according to the different load ratios and sheet thickness combinations to draw a $\Delta F_{a}-N$ (load rangelife) scatter plot (Figures 5 and 6).

\begin{tabular}{|c|c|c|c|c|}
\hline \multicolumn{2}{|c|}{$\begin{array}{l}\text { Specimen thicknesses } \\
t(\mathrm{~mm})\end{array}$} & \multirow[t]{2}{*}{$\begin{array}{l}\text { Welding nugget } \\
\text { diameter } \Phi d(\mathrm{~mm})\end{array}$} & \multicolumn{2}{|c|}{$\begin{array}{l}\text { Chamfer circle } \\
\text { radius } R(\mathrm{~mm})\end{array}$} \\
\hline$t_{1}$ & $t_{2}$ & & $R_{1}$ & $R_{2}$ \\
\hline 0.8 & 1.2 & 4.5 & 4.0 & 4.0 \\
\hline 0.8 & 2.5 & 4.5 & 4.0 & 5.0 \\
\hline 1.5 & 1.5 & 6.0 & 4.0 & 4.0 \\
\hline 1.5 & 2.0 & 6.0 & 4.0 & 5.0 \\
\hline 2.0 & 2.0 & 6.0 & 5.0 & 5.0 \\
\hline
\end{tabular}

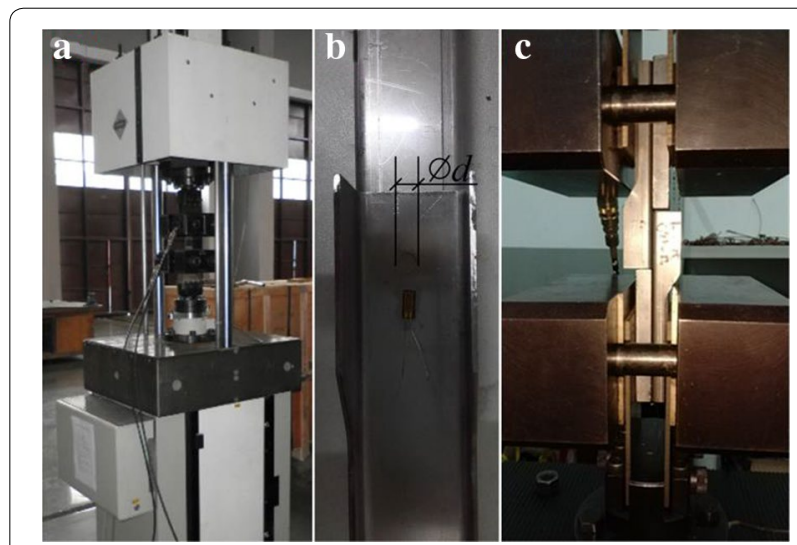

Figure 4 Testing machine and spot-welded specimen

As can be seen from Figure 6, for the spot-welded specimen with $1.5+1.5 \mathrm{~mm}$ thickness combination, the data under the load ratio $r=0.1$ are more dispersed than those under $r=0.5$ because of the influence of the average load. When the load range is constant, as the load ratio $r$ increases, the average load value also increases, which causes the increase of tensile load in the cyclic load. This is very favorable for the initiation and propagation of fatigue cracks and can reduce fatigue life. Therefore, the effect of the load ratio on fatigue strength needs to be considered.

\subsection{Finite Element Simulation}

The finite element model of the spot-welded structure was established according to the actual structural 


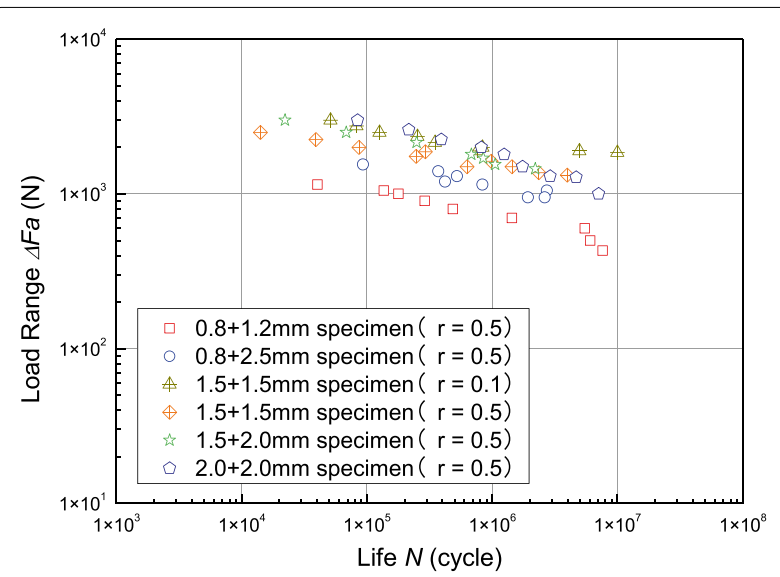

Figure $5 \Delta F_{a}-N$ scatter diagram of spot-welded specimens

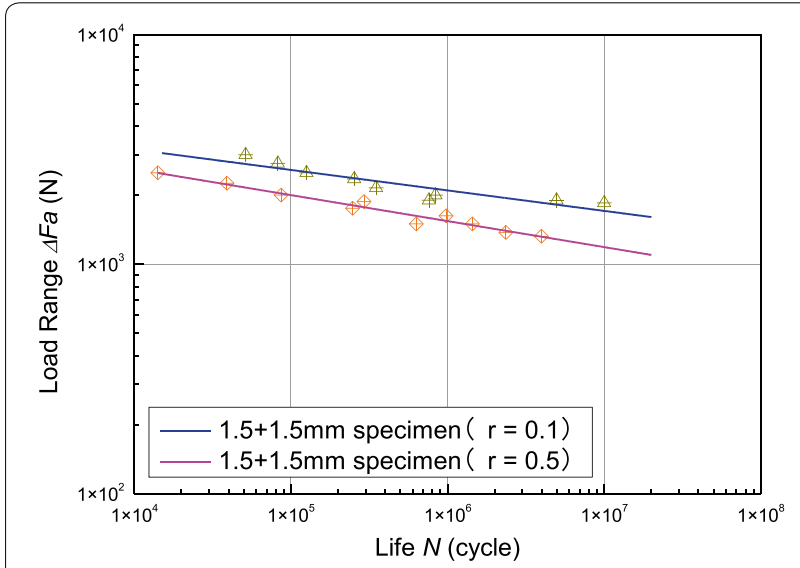

Figure 6 Fatigue data for $1.5 \mathrm{~mm}+1.5 \mathrm{~mm}$ under two load ratios $(r=0.1$ and 0.5$)$

dimension of the specimen, as shown in Figure 7. Neutral shell elements were used to simulate the two connected sheets, and a single rigid CBAR beam element was used to simulate the weld nugget. The sheet thickness of the specimens was defined as $t_{1}+t_{2}$, and the diameter of the weld nugget was assumed to be $\Phi d$ in the finite element model.

For each loading case under the load ratio $r$ and load range $\Delta F_{a}$, the maximum load $F_{\max }$ and the minimum load $F_{\min }$ were loaded into the finite element model.

The loaded model was imported into NASTRAN for calculation, and the forces and moments of the beam element nodes under $F_{\max }$ and $F_{\min }$ were obtained. Then, the results were substituted into Eqs. (1)-(7) to obtain the structural stress of the spot-welded specimens based on the tensile-shear force calculation. In Figure $8, \mathrm{~A}$ and $\mathrm{B}$ represent the nodes at the two ends of the beam element.

\subsection{Fitting the S-N Curve}

The fatigue life values of spot-welded specimens were obtained in actual fatigue tests, and the structural stress range $\Delta \sigma_{\mathrm{s}}$ was calculated according to the structural stress equations based on the finite element simulation under the tensile-shear load. By taking the structural stress range $\Delta \sigma_{\mathrm{s}}$ as the ordinate and the fatigue life $N$ as the abscissa, the double logarithmic model and the leastsquares method were used to fit the fatigue data by linear regression analyses under different loading ratios $(r=0.1$ and 0.5 ). Consequently, the S-N curves of spot-welded specimens were obtained (Figures 9 and 10). The governing equations from the regression analyses are shown in each figure.

The values of the correlation coefficient squared $\left(R^{2}\right)$ under two load ratios $(r=0.1$ and 0.5$)$ and one load ratio $(r=0.5)$ were 0.6582 and 0.8445 , respectively. There is a significant change in $\mathrm{R}^{2}$ under different loading ratios. Therefore, the influence of the load ratio on the fatigue performance should be distinguished in the research process.

According to the linear regression results under the load ratio $r=0.5$, the equation for fatigue life evaluation of the spot-welded specimens was obtained by fitting as

$$
y=-0.1694 x+3.2506,
$$

where $y=\lg \Delta \sigma_{\mathrm{s}}$ (the equivalent structural stress range) and $x=\lg N$ (the fatigue life).

According to the fitted S-N curve equation and the test data of spot welding, the residual standard deviation $\sigma=0.05097$ was calculated. The results prove that the predicted life of the curve deviates little from the test life and that the predicted result of the regression model is good.

According to the fitted S-N curve of the spot-welded specimen obtained by linear regression, with the life obtained by the test as the abscissa and the predicted life as the ordinate, the five lifespans used to predict the fatigue life are plotted, as shown in Figures 11 and 12.

Figure 11 shows that most data points fall within five lifespans with the exception of a few points. Figure 12 shows that all the data points fall within five lifespans, and the prediction result is better than that of Figure 11. It can be seen that the load ratio has a great influence on the fatigue characteristics of the base metal of the spotwelded specimen and so the fatigue data under different load ratios should be considered separately.

\section{Results and Discussion}

\subsection{Structural Stress Calculation with Correction Coefficients}

As shown in Figure 2, by taking sheet 1 as an example, the structural stress equation after introducing the correction coefficient can be expressed by 


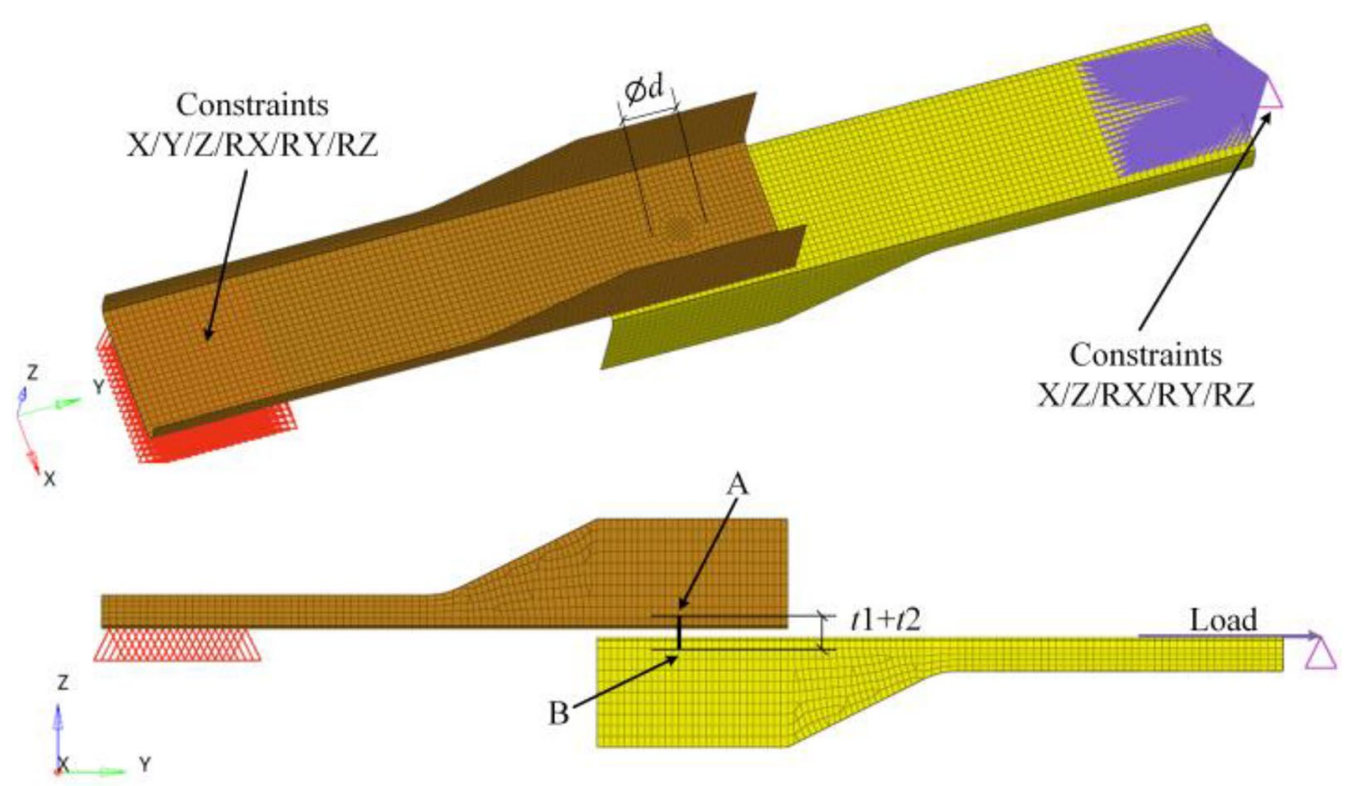

Figure 7 Finite element model for specimen

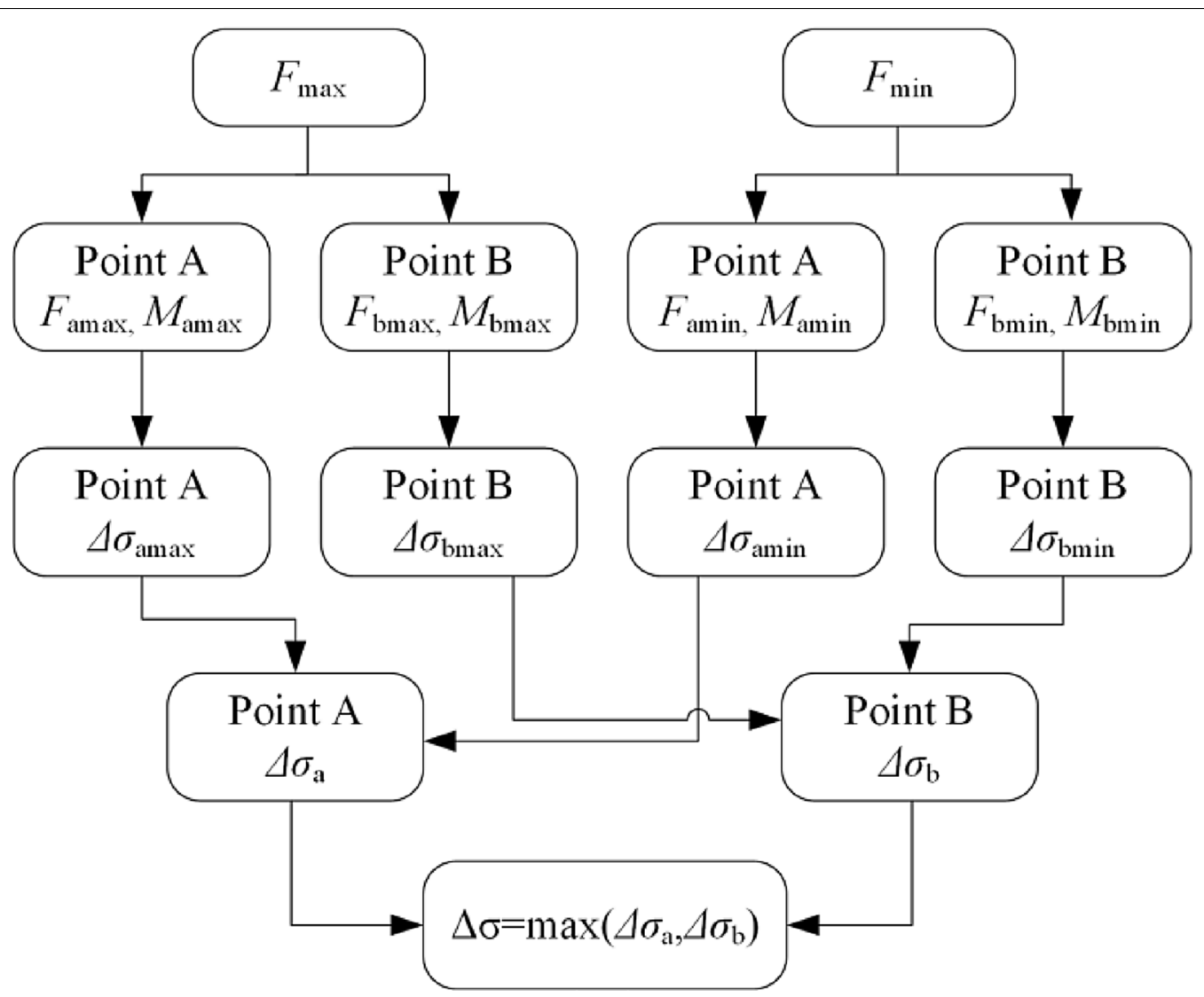

Figure 8 Process for calculating equivalent structure stress 


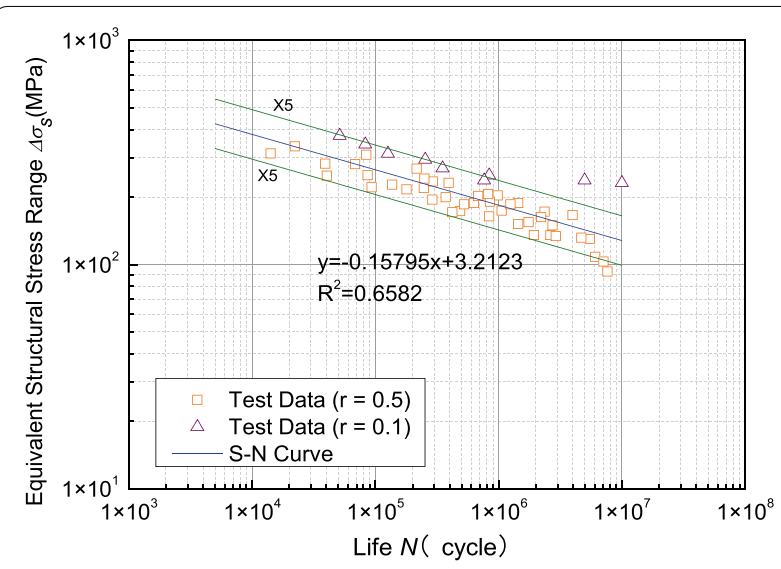

Figure 9 Correlation between equivalent structural stress range and fatigue life under tensile-shear load $(r=0.1$ and 0.5$)$

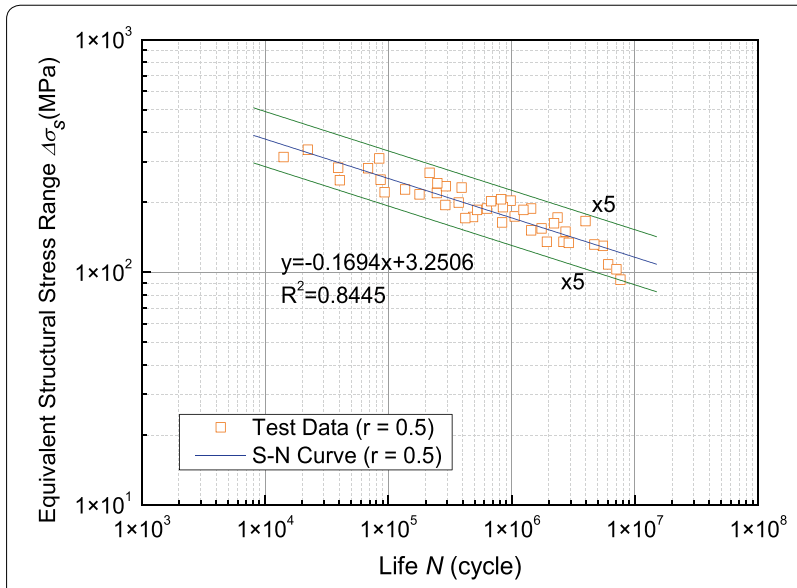

Figure 10 Correlation between equivalent structural stress range and fatigue life under tensile-shear load $(r=0.5)$

$$
\begin{array}{r}
\sigma_{v 1}=-\sigma_{\max }\left(F_{x 1}\right) \cos \theta-\sigma_{\max }\left(F_{y 1}\right) \sin \theta+\sigma_{\max }\left(F_{z 1}\right) \\
+\sigma_{\max }\left(M_{x 1}\right) \sin \theta-\sigma_{\max }\left(M_{y 1}\right) \cos \theta,
\end{array}
$$

where

$$
\begin{aligned}
& \sigma_{\max }\left(F_{x 1}\right)=\frac{F_{x 1}}{\pi d s_{1}} \times S F F X Y \times d^{D E F X Y} \times s_{1}^{T E F X Y}, \\
& \sigma_{\max }\left(F_{y 1}\right)=\frac{F_{y 1}}{\pi d s_{1}} \times S F F X Y \times d^{D E F X Y} \times s_{1}^{T E F X Y}, \\
& \sigma_{\max }\left(M_{x 1}\right)=\left(\frac{1.872 M_{x 1}}{d s_{1}^{2}}\right) \times S F M X Y \times d^{D E M X Y} \times s_{1}^{T E M X Y},
\end{aligned}
$$

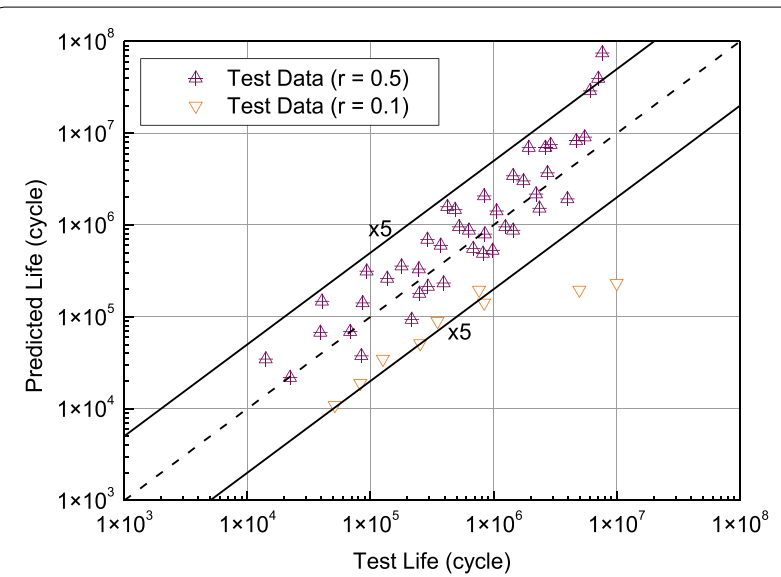

Figure 11 Test life and predicted life of spot-welded specimens without considering the load ratio

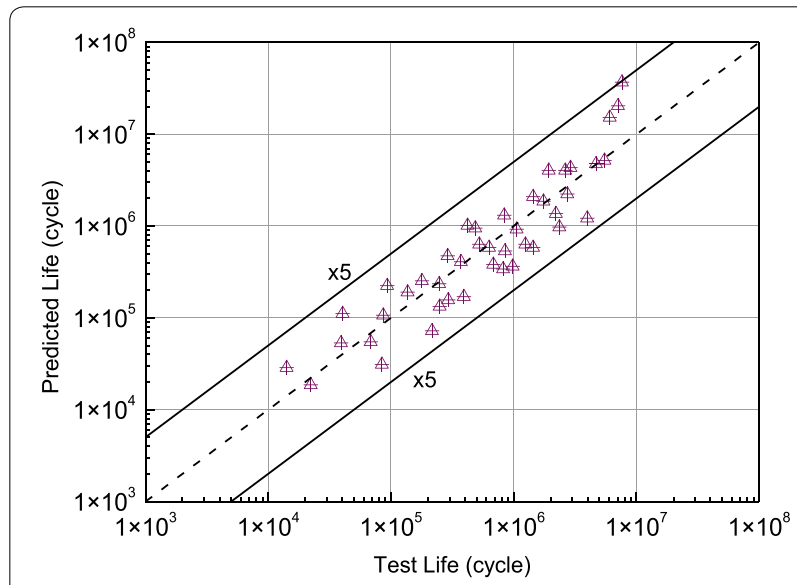

Figure 12 Test life and predicted life of spot-welded specimens under load ratio $r=0.5$

$$
\sigma_{\max }\left(M_{y 1}\right)=\left(\frac{1.872 M_{y 1}}{d s_{1}^{2}}\right) \times S F M X Y \times d^{D E M X Y} \times s_{1}^{T E M X Y},
$$

$$
\sigma_{\max }\left(F_{z 1}\right)=\left(\frac{1.744 F_{z 1}}{s_{1}^{2}}\right) \times S F F Z \times d^{D E F Z} \times s_{1}^{T E F Z} .
$$

In the structural stress solution equations for spot welding, nine parameters were introduced to modify the stress results obtained by the shear force, axial force, and bending moment. At present, the default initial values are mainly used in the project to solve for the spot-welding structural stress in steel. The default values of these parameters are given in Table 5 .

The structural stress calculated after introducing the correction coefficient and the fatigue life obtained by the test were plotted and the result is shown in Figure 13. The 
Table 5 Initial correction parameters (C1)

\begin{tabular}{lll}
\hline SFFXY & SFFZ & SFMXY \\
1 & 0.6 & 0.6 \\
DEFXY & DEFZ & DEMXY \\
0 & 0 & 0 \\
TEFXY & TEFZ & TEMXY \\
0 & 0.5 & 0.5 \\
\hline
\end{tabular}

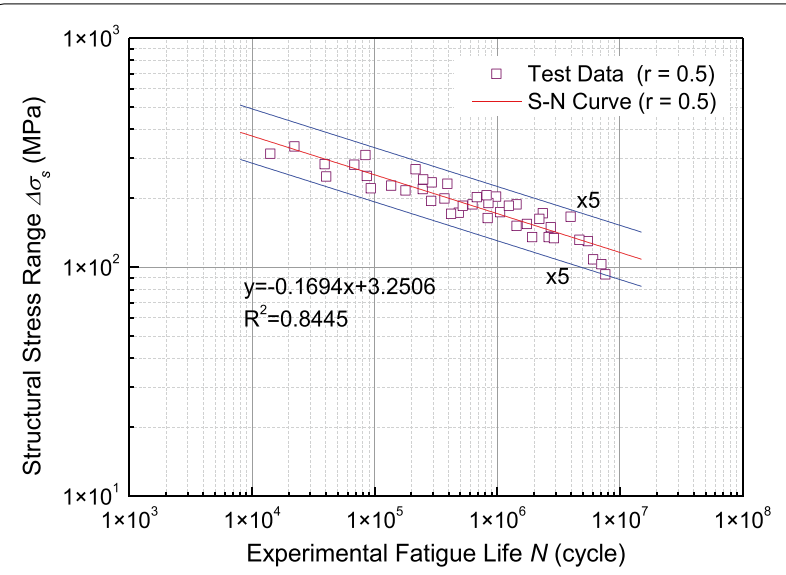

Figure 13 S-N curve of spot-welded specimens with initial correction parameter $r=0.5$

regression analysis was performed on the spot-welding test data by using the least-squares method.

In fact, spot welding is widely used in structures of railroad vehicles and the bodies and main components of automobiles. Automobiles are mainly made of thinwalled, high-strength steel and railroad vehicles are made of austenitic stainless steel. The fatigue properties of these two kinds of spot-welding structures in the two conditions are different. The initial $\mathrm{S}-\mathrm{N}$ curve is not accurate and cannot meet the requirements of the railroad vehicles. Therefore, the correction parameters should be considered, and the initial $\mathrm{S}-\mathrm{N}$ curve should be optimized to obtain a new $\mathrm{S}-\mathrm{N}$ curve that is more relevant and suitable for the spot-welding structures of railroad vehicles.

\subsection{Correction Coefficient Optimization}

According to the structural stress solution Eqs. (1)-(6), the correlation coefficient $\mathrm{R}^{2}$ of the fitted S-N curve is taken as an objective function, and the variables are the nine parameters in the structural stress solution equations, the range of which is between 0 and 1 . The parameter optimization program was compiled in MATLAB. In the program, the correction coefficients for the sheet thickness and welding nugget diameter are used

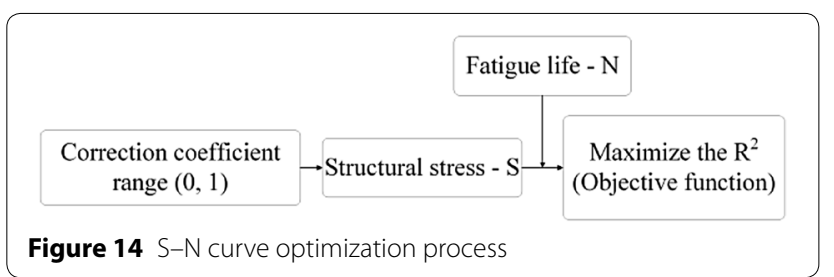

Table 6 Optimized parameters

\begin{tabular}{llll}
\hline & $\begin{array}{l}\text { Force and bending } \\
\text { moment } \\
\text { coefficients }\end{array}$ & Diameter coefficients & $\begin{array}{l}\text { Sheet } \\
\text { thickness } \\
\text { coefficients }\end{array}$ \\
\hline$F X, F Y$ & $3.81 \times 10^{-5}$ & 0.21 & 0.36 \\
$F Z$ & $2.34 \times 10^{-5}$ & 0.29 & 0.38 \\
$M X, M Y$ & 0.75 & $1.44 \times 10^{-5}$ & 0.34 \\
$R^{2}$ & 0.8784 & & \\
\hline
\end{tabular}

as variables ranging from 0 to 1 , whereby the structural stress $\mathrm{S}$ can be calculated. Then, in combination with the test fatigue life $\mathrm{N}$, the correlation coefficient squared, $\mathrm{R}^{2}$, can be maximized. Figure 14 shows the specific optimization flowchart.

The fmincon function of the nonlinear constrained optimization tool in MATLAB was used to control the maximum objective function. The quasi-Newton method (BFGS) [35] algorithm was used to optimize the obtained $\mathrm{S}-\mathrm{N}$ curve. The S-N curve was optimized under the load ratio $r=0.5$, and the optimized results are listed in Table 6.

The initial input values of the nine parameters were modified. Then the corrected parameter values and correlation coefficient values were calculated. The results are listed in Table 7.

It can be seen from Table 7 that, in the case of different initial values, the nine corrected parameters have little difference, and the correlation coefficient has no change, which indicates that the optimization procedure is correct and the obtained results are the optimal solutions in this interval.

The first two rows of the optimization results were shear force and axial force parameters. The values are close to zero. When these values are put into the formulas of the structural stress solution, the obtained $\sigma_{\max }\left(F_{x}\right)$ and $\sigma_{\max }\left(F_{y}\right)$ are also close to zero. This means that the influence of the shear force and the axial force on structural stress has been ignored, which is incorrect. In response to this problem, three specific optimization methods were performed. 
Table 7 Optimization results under different initial inputs

\begin{tabular}{llll}
\hline & First results & Second results & Third results \\
\hline SFFXY & $3.24 \times 10^{-5}$ & $3.37 \times 10^{-5}$ & $3.79 \times 10^{-5}$ \\
SFFZ & $2.14 \times 10^{-5}$ & $2.10 \times 10^{-5}$ & $2.28 \times 10^{-5}$ \\
SFMXY & 0.75 & 0.72 & 0.75 \\
DEFXY & 0.26 & 0.23 & 0.21 \\
DEFZ & 0.32 & 0.32 & 0.29 \\
DEMXY & $1.44 \times 10^{-5}$ & $1.44 \times 10^{-5}$ & $1.44 \times 10^{-5}$ \\
TEFXY & 0.41 & 0.39 & 0.4 \\
TEFZ & 0.41 & 0.39 & 0.39 \\
TEMXY & 0.34 & 0.34 & 0.34 \\
$R^{2}$ & 0.8784 & 0.8784 & 0.8784 \\
\hline
\end{tabular}

\subsubsection{Force and Moment Correction (C2)}

In reference to Eqs. (9)-(14) for the correction of the welding nugget diameter and sheet thickness, the correction of the force and moment can be expressed as

$$
\begin{aligned}
\sigma_{\max }\left(F_{x 1}\right)= & \frac{F_{x 1}}{\pi d s_{1}} \times\left|F_{x 1}\right|^{S F F X Y} \times d^{D E F X Y} \times s_{1}^{T E F X Y}, \\
\sigma_{\max }\left(F_{y 1}\right)= & \frac{F_{y 1}}{\pi d s_{1}} \times\left|F_{y 1}\right|^{S F F X Y} \times d^{D E F X Y} \times s_{1}^{T E F X Y}, \\
\sigma_{\max }\left(M_{x 1}\right)= & \left(\frac{1.872 M_{x 1}}{d s_{1}^{2}}\right) \times\left|M_{x 1}\right|^{S F M X Y} \\
& \times d^{D E M X Y} \times s_{1}^{T E M X Y}, \\
\sigma_{\max }\left(M_{y 1}\right)= & \left(\frac{1.872 M_{y 1}}{d s_{1}^{2}}\right) \times\left|M_{y 1}\right|^{S F M X Y} \\
& \times d^{D E M X Y} \times s_{1}^{T E M X Y}, \\
\sigma_{\max }\left(F_{z 1}\right)= & \left(\frac{1.744 F_{z 1}}{s_{1}^{2}}\right) \times\left|F_{z 1}\right|^{S F F Z} \times d^{D E F Z} \times s_{1}^{T E F Z} .
\end{aligned}
$$

According to Eqs. (15)-(19), the S-N curve of spot welding under load ratio $r=0.5$ was re-optimized. The results of parameter optimization are listed in Table 8.

The optimized results were brought into the structural stress equations to re-solve for the structural stress. The $\mathrm{S}-\mathrm{N}$ curve equation of the spot-welded specimen under tensile-shear load is $y=0.17493 x+3.4901$, with $\mathrm{R}^{2}=0.8906$.
Table 8 Parameter optimization results (C2)

\begin{tabular}{lll}
\hline SFFXY & SFFZ & SFMXY \\
0.0456 & $1.07 \times 10^{-5}$ & 0.023 \\
DEFXY & DEFZ & DEMXY \\
$2.77 \times 10^{-5}$ & $2.65 \times 10^{-5}$ & $1.44 \times 10^{-5}$ \\
TEFXY & TEFZ & TEMXY \\
$4.58 \times 10^{-5}$ & $7.95 \times 10^{-5}$ & $4 \times 10^{-4}$ \\
\hline
\end{tabular}

\subsubsection{Force and Moment Correction with Initial Empirical Coefficient $K_{1}(C 3)$}

Based on Eqs. (9)-(11), the initial empirical correction coefficient $K_{1}$ was introduced, and the structural stress equations are as follows:

$$
\begin{aligned}
\sigma_{\max }\left(F_{x 1}\right)= & \frac{F_{x 1}}{\pi d s_{1}} \times\left|F_{x 1}\right|^{S F F X Y} \times d^{D E F X Y} \times s_{1}^{T E F X Y}, \\
\sigma_{\max }\left(F_{y 1}\right)= & \frac{F_{y 1}}{\pi d s_{1}} \times\left|F_{y 1}\right|^{S F F X Y} \times d^{D E F X Y} \times s_{1}^{T E F X Y}, \\
\sigma_{\max }\left(M_{x 1}\right)= & K_{1} \times\left(\frac{1.872 M_{x 1}}{d s_{1}^{2}}\right) \times\left|M_{x 1}\right|^{S F M X Y} \\
& \times d^{D E M X Y} \times s_{1}^{T E M X Y}, \\
\sigma_{\max }\left(M_{y 1}\right)= & K_{1} \times\left(\frac{1.872 M_{y 1}}{d s_{1}^{2}}\right) \times\left|M_{y 1}\right|^{S F M X Y} \\
& \times d^{D E M X Y} \times s_{1}^{T E M X Y}, \\
\sigma_{\max }\left(F_{z 1}\right)=K_{1} & \times\left(\frac{1.744 F_{z 1}}{s_{1}^{2}}\right) \times\left|F_{z 1}\right|^{S F F Z} \times d^{D E F Z} \times s_{1}^{T E F Z} .
\end{aligned}
$$

According to Eqs. (20)-(24), the S-N curve of spot welding under load ratio $r=0.5$ was re-optimized. The parameter optimization results are listed in Table 9.

The optimized results were brought into the structural stress equations to re-solve for the structural stress. The $\mathrm{S}-\mathrm{N}$ curve equation of the spot-welded specimen under tensile-shear load is $y=0.16948 x+3.2811$, with $\mathrm{R}^{2}=0.8573$.

\subsubsection{Welding Nugget Diameter and Sheet Thickness Correction (C4)}

The coefficients for the force and moment in Table 4 were used to change the other six parameters, such as the welding nugget diameter and sheet thickness in the equations, and the structural stress equations are as follows: 
Table 9 Parameter optimization results (C3)

\begin{tabular}{lll}
\hline SFFXY & SFFZ & SFMXY \\
0.02 & $5.95 \times 10^{-7}$ & $4.11 \times 10^{-7}$ \\
DEFXY & DEFZ & DEMXY \\
$2.46 \times 10^{-6}$ & $1.92 \times 10^{-6}$ & $1.04 \times 10^{-6}$ \\
TEFXY & TEFZ & TEMXY \\
$1.17 \times 10^{-6}$ & $3.28 \times 10^{-6}$ & $7.06 \times 10^{-7}$ \\
\hline
\end{tabular}

Table 10 Parameter optimization results (C4)

\begin{tabular}{lll}
\hline DEFXY & DEFZ & DEMXY \\
$1.84 \times 10^{-5}$ & $3.49 \times 10^{-5}$ & 0.13 \\
TEFXY & TEFZ & TEMXY \\
$2.3 \times 10^{-4}$ & $1.5 \times 10^{-4}$ & $2 \times 10^{-4}$ \\
\hline
\end{tabular}

$$
\begin{aligned}
& \sigma_{\max }\left(F_{x 1}\right)=\frac{F_{x 1}}{\pi d s_{1}} \times d^{D E F X Y} \times s_{1}^{T E F X Y}, \\
& \sigma_{\max }\left(F_{y 1}\right)=\frac{F_{y 1}}{\pi d s_{1}} \times d^{D E F X Y} \times s_{1}^{T E F X Y}, \\
& \sigma_{\max }\left(M_{x 1}\right)=\left(\frac{1.872 M_{x 1}}{d s_{1}^{2}}\right) \times d^{D E M X Y} \times s_{1}^{T E M X Y},
\end{aligned}
$$$$
\sigma_{\max }\left(M_{y 1}\right)=\left(\frac{1.872 M_{y 1}}{d s_{1}^{2}}\right) \times d^{D E M X Y} \times s_{1}^{T E M X Y}
$$$$
\sigma_{\max }\left(F_{z 1}\right)=\left(\frac{1.744 F_{z 1}}{s_{1}^{2}}\right) \times d^{D E F Z} \times s_{1}^{T E F Z}
$$

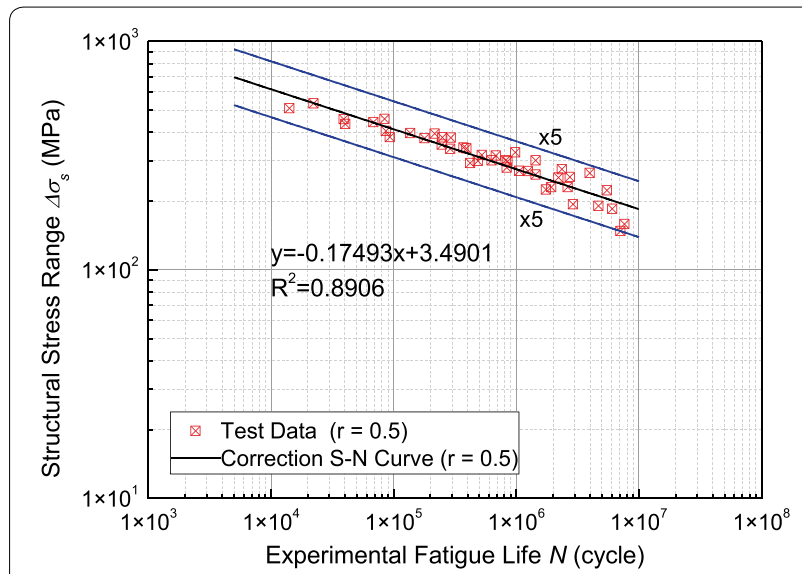

Figure 15 S-N curve of spot-welded specimens under correction load ratio $r=0.5$ (C2)

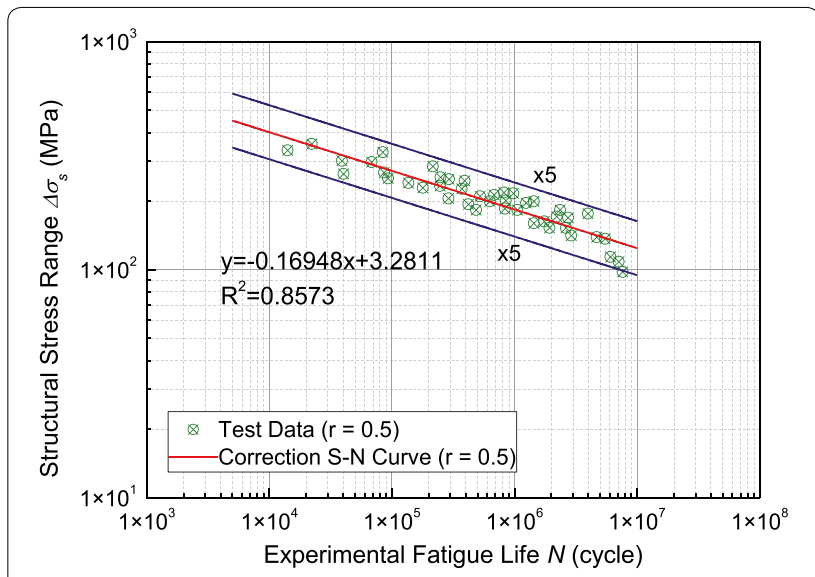

Figure $16 \mathrm{~S}-\mathrm{N}$ curve of spot-welded specimens under correction load ratio $r=0.5$ (C3)

According to the structural stress Eqs. (25)-(29), the $\mathrm{S}-\mathrm{N}$ curve of spot welding under load ratio $r=0.5$ was re-optimized. The parameter optimization results are listed in Table 10.

The optimized results were brought into the structural stress equations to re-solve for the structural stress. The $\mathrm{S}-\mathrm{N}$ curve equation of the spot-welded specimen under tensile-shear load is $y=0.17041 x+3.2622$, with $\mathrm{R}^{2}=0.8874$.

Comparing Figure 13 with Figures 15, 16, 17, it can be found that, after three types of corrections, the correlation coefficients of the spot-welding $\mathrm{S}-\mathrm{N}$ curves increased, and all the test data points fall within five lifespans.

The results of the four optimization methods and the optimization parameters are listed in Table 11 and Table 12, respectively. $\mathrm{C} 1$ has no optimization. $\mathrm{C} 2$ has the removal of the initial empirical coefficient $K_{1}$ and

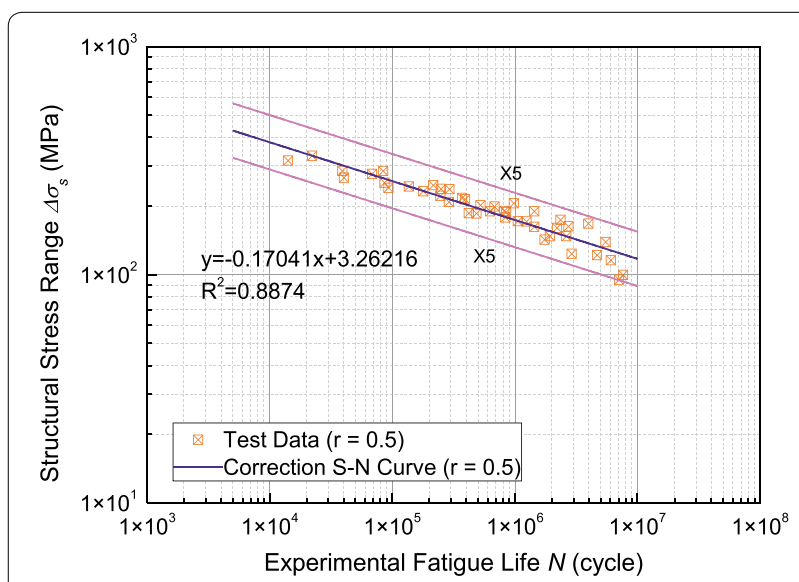

Figure 17 S-N curve of spot-welded specimens under correction load ratio $r=0.5$ (C4) 
Table 11 Results of four optimization methods

\begin{tabular}{lll}
\hline $\begin{array}{l}\text { Optimization } \\
\text { methods }\end{array}$ & S-N curve & $\mathbf{R}^{\mathbf{2}}$ \\
\hline C1 & $\lg S=-0.1694 \lg N+3.2506$ & 0.8445 \\
C2 & $\lg S=-0.17493 \lg N+3.4901$ & 0.8906 \\
C3 & $\lg S=-0.16948 \lg N+3.2811$ & 0.8573 \\
C4 & $\lg S=-0.1704 \lg N+3.26216$ & 0.8874 \\
\hline
\end{tabular}

Table 12 Optimization parameters of four optimization methods

\begin{tabular}{lllll}
\hline $\begin{array}{l}\text { Optimization } \\
\text { method }\end{array}$ & C1 & C2 & C3 & C4 \\
\hline SFFXY & 1 & 0.0456 & 0.02 & - \\
SFFZ & 0.6 & $1.07 \times 10^{-5}$ & $5.95 \times 10^{-7}$ & - \\
SFMXY & 0.6 & 0.023 & $4.11 \times 10^{-7}$ & - \\
DEFXY & 0 & $2.77 \times 10^{-5}$ & $2.46 \times 10^{-6}$ & $1.84 \times 10^{-5}$ \\
DEFZ & 0 & $2.65 \times 10^{-5}$ & $1.92 \times 10^{-6}$ & $3.49 \times 10^{-5}$ \\
DEMXY & 0 & $1.44 \times 10^{-5}$ & $1.04 \times 10^{-6}$ & 0.13 \\
TEFXY & 0 & $4.58 \times 10^{-5}$ & $1.17 \times 10^{-6}$ & $2.30 \times 10^{-4}$ \\
TEFZ & 0.5 & $7.95 \times 10^{-5}$ & $3.28 \times 10^{-6}$ & $1.50 \times 10^{-4}$ \\
TEMXY & 0.5 & $4.00 \times 10^{-4}$ & $7.06 \times 10^{-7}$ & $2.00 \times 10^{-4}$ \\
\hline
\end{tabular}

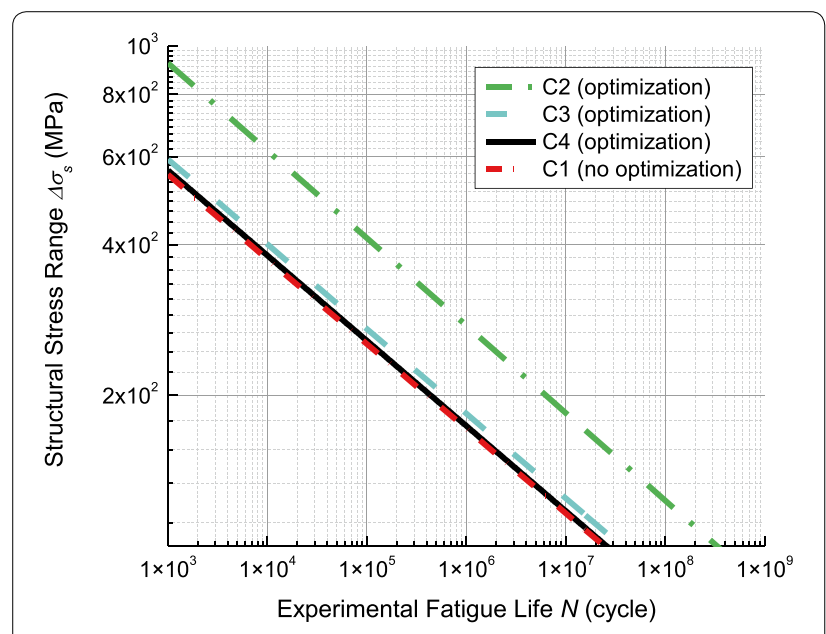

Figure 18 Comparison of S-N curves with different optimization methods

the introduction of the force and moment correction. C3 has the retention of the initial empirical coefficient $K_{1}$ and the introduction of the force and moment correction. $\mathrm{C} 4$ has the correction of the welding nugget diameter and sheet thickness.

The $\mathrm{S}-\mathrm{N}$ curves of the four optimization methods were compared, as shown in Figure 18. It can be seen that $\mathrm{C} 3$ and $\mathrm{C} 4$ are close to the original curve, whereas $\mathrm{C} 2$ exhibits an obvious difference.

\section{Conclusions}

According to the fatigue test results, the following conclusions can be drawn by analyzing the fatigue failure characteristics of spot-welded specimens.

With the value of the correlation coefficient squared, $R^{2}$, as the objective function, three optimization methods are proposed to optimize the $\mathrm{S}-\mathrm{N}$ curves under the load ratio $r=0.5$. After three corrections, the $\mathrm{S}-\mathrm{N}$ curve correlation coefficient of the spot-welding structure is increased. The data points are compact and all of them fall within five lifespans. The optimization effect is remarkable, and the obtained $\mathrm{S}-\mathrm{N}$ curves can be used to predict the fatigue life.

The $\mathrm{S}-\mathrm{N}$ curves obtained in this study are applicable to the fatigue lives of spot-welded structures under the load ratio $r=0.5$, a base metal of EN1.4318, and sheet thicknesses of $0.8-2.5 \mathrm{~mm}$.

When the types of loads, diameters and sheet thicknesses are various in the test, using $\mathrm{C} 2$ optimization is recommended; if the load type is relatively limited, $\mathrm{C} 4$ is recommended for optimization; if the test data are relatively limited, using C3 optimization is recommended.

\section{Acknowledgements}

Not applicable.

\section{Authors' contributions}

GY was in charge of the whole trial; $Y Q$ wrote the manuscript and guided the numerical simulations; XL assisted with sampling and laboratory analyses; SX, $L L$ and $B Y$ guided the experiments. All authors read and approved the final manuscript.

\section{Authors' Information}

Yahang Qin, born in 1990, is currently a PhD candidate at State Key Laboratory of Traction Power, Southwest Jiaotong University, China. He received his bachelor degree from Southwest Jiaotong University, China, in 2013. His research interests include vehicle structure strength and fatigue life prediction.

Shoune Xiao, born in 1964, is currently a professor at State Key Laboratory of Traction Power, Southwest Jiaotong University, China. He received his master degree on Solid Mechanics in Southwest Jiaotong University, China, in 1988. His main research interests include vehicle structure strength and structural optimization.

Liantao Lu, born in 1965, is currently a professor and a PhD candidate supervisor at State Key Laboratory of Traction Power, Southwest Jiaotong University, China. He received his PhD degree from University of Toyama, Japan, in 2003. His main research interests include vehicle structure fatigue and fracture, material fatigue

Bing Yang, born in 1979, is currently an associate professor at State Key Laboratory of Traction Power, Southwest Jiaotong University, China. He received his PhD degree from Southwest Jiaotong University, China, in 2011. His research interests include strength of vehicle structure and fatigue and fracture of materials.

Xiangjie Li, born in 1994, is currently a master candidate at State Key Laboratory of Traction Power, Southwest Jiaotong University, China.

Guangwu Yang, born in 1977, is currently a professor at State Key Laboratory of Traction Power, Southwest Jiaotong University, China. He received his PhD degree on Vehicle Engineering in Southwest Jiaotong University, China, in 2005. His main research interests include vehicle structure strength and fatigue reliability. 


\section{Funding}

Supported by National Natural Science Foundation of China (Grant Nos. U1534209, 51675446), and Independent Subject of State Key Laboratory of Traction Power (Grant No. 2019TPL-T13).

\section{Competing interests}

The authors declare no competing financial interests.

Received: 17 September 2019 Revised: 30 March 2020 Accepted: 16 April 2020

Published online: 01 May 2020

\section{References}

[1] H-T Kang. Fatigue prediction of spot welded joints using equivalent structural stress. Materials and Design, 2007, 28(3): 837-843.

[2] H-T Kang, P-S Dong, J K Hong. Fatigue analysis of spot welds using a mesh-insensitive structural stress approach. International Journal of Fatique, 2007, 29(8): 1546-1553.

[3] D Radaj. Local fatigue strength characteristic values for spot welded joints. Engineering Fracture Mechanics, 1990, 37(1): 245-250.

[4] A Rupp, Störzel K, V Grubisic. Computer aided dimensioning of spotwelded automotive structures. SAE Transactions, 1995.

[5] H-T Kang, X Wu, AK Khosrovaneh, et al. Data processing procedure for fatigue life prediction of spot-welded joints using a structural stress method. In: Fatigue and Fracture Test Planning, Test Data Acquisitions and Analysis, Z Wei, K Nikbin, P McKeighan, and D Harlow, ed. (West Conshohocken, PA: ASTM International, 2017), 198-211. http://www.astm.org/ doi:10.1520/STP159820160054.

[6] H-T Kang, X Wu. Structural stress correction methods for linear elastic finite element analysis of spot welded joints. ASME 2016 International Mechanical Engineering Congress and Exposition, Phoenix, Arizona, USA, November 11-17, 2016, https://doi.org/10.1115/imece2016-66884.

[7] H F Henrysson. Fatigue life predictions of spot welds using coarse FE meshes. Fatigue \& Fracture of Engineering Materials \& Structures, 2000, 23 : 737-746.

[8] T Zhu, S N Xiao, G W Yang, et al. Fatigue life prediction of spot-welded structure under different finite element models of spot-weld. Advanced Materials Research, 2010, 118-120: 191-195.

[9] Andersson, A Melander. Prediction and verification of resistance spot welding results of ultra-high strength steels through FE simulations. Modeling \& Numerical Simulation of Material Science, 2015, 5: 26-37.

[10] DW Zhao, Y X Wang, D J Liang, et al. Modeling and process analysis of resistance spot welded DP600 joints based on regression analysis. Materials \& Design, 2016, 110: 676-684.

[11] M S M Sani, N A Nazri, et al. Vibration analysis of resistance spot welding joint for dissimilar plate structure (mild steel 1010 and stainless steel 304). IOP Conference Series: Materials Science and Engineering, 2017, 238.

[12] W Noh, W Kim, et al. Simple and effective failure analysis of dissimilar resistance spot welded advanced high strength steel sheets. International Journal of Mechanical Sciences, 2017, 121: 76-89.

[13] N Wooram, K Youngwoo, C Kwansoo et al. Influence of dynamic loading on failure behavior of spot welded automotive steel sheets. International Journal of Mechanical Sciences, 2018, 144: 407-426.

[14] N Charde, R Ahmad, N I Z Abidin. Interpreting the weld formations using acoustic emission for the carbon steels and stainless steels welds in servo-based resistance spot welding. International Journal of Advanced Manufacturing Technology, 2016, 86: 1-8.

[15] A K Pandey, M I Khan, K M Moeed. Optimization of resistance spot welding parameters using Taguchi method. International Journal of Engineering Science \& Technology, 2013, 5(2): 234-241.
[16] A Yürük, N Kahraman. Weld zone characterization of stainless steel joined through electric resistance spot welding. International Journal of Advanced Manufacturing Technology. 2017, 92(5-8): 2975-2986. https:// doi.org/10.1007/s00170-017-0335-9.

[17] M Brožek, A Nováková, O Niedermeier. Resistance spot welding of stee sheets of the same and different thickness. Acta Universitatis Agriculturae Et Silviculturae Mendelianae Brunensis, 2017, 65(3): 807-814.

[18] H M Rao, J Kang, L Shi, et al. Effect of specimen configuration on fatigue properties of dissimilar aluminum to steel resistance spot welds. International Journal of Fatigue, 2018, 116: 13-21.

[19] H Adib. Fatigue life duration prediction for welded spots by volumetric method. International Journal of Fatigue, 2004, 26(1): 81-94.

[20] B H Choi, D H Joo, S H Song. Observation and prediction of fatigue behavior of spot welded joints with triple thin steel plates under tensileshear loading. International Journal of Fatigue, 2007, 29(4): 620-627.

[21] Y-R Kan. Fatigue resistance of spotwelds-an analytical study. Metals Eng. Quart, 1976, 16: 26-36.

[22] H Oh. Fatigue-life prediction for spotweld using Neuber's Rule. In: Design of Fatigue and Fracture Resistant Structures, P Abelkis, C Hudson, ed. (West Conshohocken, PA: ASTM International, 1982), 296-309. https://doi. org/10.1520/stp28865s.

[23] N Pan, S Sheppard. Spot welds fatigue life prediction with cyclic strain range. International Journal of Fatigue, 2002, 24(5): 519-528.

[24] P Dong. A structural stress definition and numerical implementation for fatigue analysis of welded joints. International Journal of Fatigue, 2001 23(10): 865-876.

[25] P Dong, S Song, J Zhang. Analysis of residual stress relief mechanisms in post-weld heat treatment. International Journal of Pressure Vessels and Piping, 2014, 122: 6-14.

[26] X Pei, P Dong, S Xing. A structural strain parameter for a unified treatment of fatigue behaviors of welded components. International Journal of Fatigue, 2019, 124: 444-460.

[27] P C Wang, H T Corten, F V Lawrence. A fatigue life prediction method for tensile-shear spot welds. SAE Transactions, 1985, 94(3): 106-113.

[28] H Lee, N Kim, T S Lee. Overload failure curve and fatigue behavior of spot-welded specimens. Engineering Fracture Mechanics, 2005, 72(8): 1203-1221.

[29] J H Song, H Huh. Failure characterization of spot welds under combined axial-shear loading conditions. International Journal of Mechanical Sciences, 2011, 53: 513-525.

[30] F Esmaeili, A Rahmani, S Barzegar, et al. Prediction of fatigue life for multispot welded joints with different arrangements using different multiaxial fatigue criteria. Materials \& Design, 2015, 72: 21-30.

[31] S J Sung, J Chen, J Pan. Stress intensity factor solutions for similar and dissimilar spot welds in lap-shear specimens under clamped loading conditions. Engineering Fracture Mechanics, 2017, 179: 328-347.

[32] D Kianersi, A Mostafaei, A A Amadeh. Resistance spot welding joints of AISI 316L austenitic stainless steel sheets: Phase transformations, mechanical properties and microstructure characterizations. Materials \& Design, 2014, 61: 251-263.

[33] S Dancette, D Fabrègue, V Massardier, et al. Experimental and modeling investigation of the failure resistance of Advanced High Strength Steels spot welds. Engineering Fracture Mechanics, 2011, 78(10): 2259-2272.

[34] The European Committee for Standardization, BS EN 10088-2:2014. Stainless steels - Part 2: Technical delivery conditions for sheet/plate and strip of corrosion resisting steels for general purposes. British Standards Institution, 2014.

[35] C G Broyden. Quasi-Newton methods and their application to function minimization. Mathematics of Computation, 1967, 21(99): 368-381. 